\title{
2 State of the art - conceptualising environmental policy convergence
}

\author{
KATHARINA HOLZINGER, HELGE JÖRGENS \\ AND CHRISTOPH KNILL
}

\section{I INTRODUCTION}

The study of policy convergence has received considerable attention both in comparative politics and in the field of international studies. Interestingly, both disciplines have approached the subject from opposite starting points and with differing methodologies. Whereas in the field of international studies theoretically derived expectations of an increasing similarity of states and political systems driven by economic or ideational forces constituted a dominant thread in the early convergence literature (for a comprehensive overview see Drezner 2001), comparative studies initially focused more on the explanation of empirically observed differences between national political systems and programmes (Lundqvist 1974, 1980). Only recently have the two research strands effectively merged into an integrated study of policy convergence that increasingly challenges the traditional boundaries between comparative politics and international relations.

In this chapter we first introduce the concept of policy convergence and explain how it relates to similar concepts like policy transfer, policy diffusion or isomorphism. In a second step we review the existing empirical research on environmental policy convergence both in comparative politics and in international relations. Based on this overview, and drawing more broadly on the general convergence literature, we systematise the major causes of policy convergence that have been identified in these studies. We distinguish between causal mechanisms which translate pressures at the international level into domestic policy change and, possibly, into convergence of domestic policies, 
and facilitating factors which operate at the level of individual countries or specific policies. By including not only processes at the international level which have been stressed mainly by scholars of international relations, but also country-specific factors which lie at the core of most studies in the field of comparative politics, we attempt to cross the borders of these two disciplines. In the end we develop a heuristic typology which illustrates how the different causal factors and mechanisms may relate to the phenomenon of policy convergence. This typology provides a useful analytical and heuristic tool both for quantitative studies on policy convergence as they are presented in this book and for qualitative case studies which ideally should complement quantitative approaches.

\subsection{POLICY CONVERGENCE AND RELATED CONCEPTS}

While there is a broad consensus on the definition of policy convergence as 'the tendency of policies to grow more alike, in the form of increasing similarity in structures, processes, and performances' (Drezner 2001: 53, see also Kerr 1983: 3), the empirical and theoretical assessment of policy convergence is generally hampered by the use of different, partially overlapping concepts (Tews 2005a). Policy convergence is often used interchangeably with related notions, such as isomorphism, policy diffusion or policy transfer, a practice that often leads to terminological and eventually even to analytical confusion. Thus, in spite of the general proximity of these concepts, a thorough analysis needs to acknowledge that these concepts stand for analytically distinct fields of study. In the following we will point out the differences between the concepts of policy diffusion, transfer and isomorphism according to four important dimensions: their analytical focus, their empirical focus, their dependent variable and their level of analysis (for an overview, see table 2.1). In doing so, we will demonstrate how they relate to the idea of policy convergence, which stands at the centre of our own analysis in this book.

The study of policy transfer emerged in the early 1990 s as a sub-field of comparative politics (Dolowitz and Marsh 1996, 2000; 
Table 2.1 Policy convergence and related concepts

\begin{tabular}{|c|c|c|c|c|}
\hline & $\begin{array}{l}\text { Policy } \\
\text { convergence }\end{array}$ & Isomorphism & Policy transfer & Policy diffusion \\
\hline $\begin{array}{l}\text { Analytical } \\
\text { focus }\end{array}$ & effects & elfects & process & process \\
\hline $\begin{array}{l}\text { Empirical } \\
\text { focus }\end{array}$ & $\begin{array}{l}\text { policy } \\
\text { characteristics }\end{array}$ & $\begin{array}{l}\text { organisational } \\
\text { structures }\end{array}$ & $\begin{array}{l}\text { policy } \\
\text { characteristics }\end{array}$ & $\begin{array}{l}\text { policy } \\
\text { characteristics }\end{array}$ \\
\hline $\begin{array}{c}\text { Dependent } \\
\text { variable }\end{array}$ & $\begin{array}{l}\text { similarity } \\
\text { change }\end{array}$ & $\begin{array}{l}\text { similarity } \\
\text { change }\end{array}$ & $\begin{array}{l}\text { transfer content } \\
\text { transfer } \\
\text { process }\end{array}$ & adoption pattern \\
\hline
\end{tabular}

Source: adapted from Knill 2005: 768.

Radaelli 2000; Rose 1991, 1993). Dolowitz and Marsh (2000: 5) define policy transfer as 'the process by which knowledge about policies, administrative arrangements, institutions and ideas in one political system (past or present) is used in the development of policies, administrative arrangements, institutions and ideas in another political system'. The analytical focus of studies of policy transfer therefore is on processes rather than results. Their level of analysis is the individual country - or any other political system - which applies information about the policies of other political units. As policy transfer is not restricted to merely imitating policies of other countries, but can include profound changes in the content of the exchanged policies (Kern, Jörgens and Jänicke 2000; Rose 1991), policy transfer studies, more than the other types of study, place a strong empirical focus on the characteristics of policies and how they change during the transfer process.

Due to its micro-level perspective and due to its concern with the modification of policies during the transfer process, the relation of policy transfer to policy convergence is only an indirect one: policy transfer may, but need not, lead to cross-national policy convergence. Methodologically, the micro-perspective inherent in the concept of policy transfer is mirrored in the predominance of case studies within this field of study. Generally, these case studies concentrate on one 
or a few countries, describing and analysing in depth the process by which foreign policy experiences are used or even imitated domestically. They focus on the actors and institutions that promote or constrain the adoption of external policies and ask how the specific features of the policy at hand affect its transferability. Their major dependent variables, therefore, are the process and content of individual instances of policy transfer.

Similar to transfer, policy diffusion typically refers to processes rather than outcomes (Elkins and Simmons 2005). Essentially, diffusion studies explore how policies, programmes and ideas travel among a large number of political systems. However, while some studies equate diffusion with the more general notion of spread (Eyestone 1977; for a recent example see Marcussen 2005), there is a growing scholarly consensus to restrict the concept of diffusion to those cases where different national adoptions of one and the same policy or programme are directly connected to one another. Diffusion then occurs when a policy decision taken by one government leads other governments to take a similar decision (Simmons and Elkins 2004: 171-2). Policy diffusion, in other words, is the result of multilateral interdependence. This narrower usage is supported by Everett Rogers' [Rogers 2003: 5] seminal definition of diffusion as 'the process by which an innovation is communicated through certain channels over time'. The main focus of policy diffusion studies thus lies on the mechanisms by which policy innovations are communicated among a larger number of countries.

There is, however, a still ongoing dispute among diffusion scholars as to the interpretation of 'communication' and 'interdependence'. For one group of scholars, diffusion includes all conceivable channels of influence between countries, for example (1) the voluntary adoption of policy models that have been communicated in the international system, (2) diffusion processes triggered by legally binding harmonisation requirements defined in international agreements or in supranational regulations and $(3)$ the imposition of policies on other countries through external actors (for recent 
examples see Meseguer 2005, who distinguishes between horizontal and top-down mechanisms of diffusion, and Radaelli 2005). According to this concept of diffusion, no distinction of different forms of cross-national interlinkages and processes of influence is made. In contrast to this definition and more recently, a second group of scholars suggests a narrower focus of the concept, explicitly restricting diffusion to processes of voluntary policy transfer (Braun and Gilardi 2006; Busch and Jörgens 2005c; Elkins and Simmons 2005; Jörgens 2004; Kern 2000; Tews 2005a). In this view, '(d)iffusion is the spreading of innovations due to communication instead of hierarchy or collective decision-making within international institutions' (Tews 2005b: 65). Consequently, diffusion is conceived as a distinctive group of causal factors that drive international policy convergence rather than a general process that is caused by the operation of varying (voluntary, obligatory and coercive) influence channels. It comprises various mechanisms such as imitation, learning, persuasion, contagion, socialisation or 'taken-for-grantedness' (Braun and Gilardi 2006; Busch, Jörgens and Tews 2005). Diffusion, in this narrower understanding, is only one of several classes of mechanisms that may contribute to cross-national policy convergence. Other possible convergence mechanisms not included within the notion of diffusion are legal harmonisation through international accords, coercive imposition through economic or political conditionality, or similar, but independent, national decision-making.

We are thus confronted with two different conceptions of policy diffusion. On the one hand, the concept describes the process of spreading policies across countries with the possible result of cross-national policy convergence, regardless of the causal factors that are driving this development le.g., regulatory competition, international harmonisation, imposition). On the other hand, diffusion is conceived as a distinctive causal factor leading to policy convergence by means of voluntary transfer of policy models (in contrast to obliged or imposed forms of transfer|. Both conceptions of diffusion 
are analytically well-grounded and applied in the literature; it is therefore more important to point out their differences than to argue in favour of one or the other approach.

Policy diffusion and policy transfer share the assumption that governments do not learn about policy practices randomly, but rather through common affiliations, negotiations and institutional membership (Simmons and Elkins 2004). Both transfer and diffusion processes hence require that actors are informed about the policy choices of others (Strang and Meyer 1993: 488). Given these conceptual overlaps, diffusion is often equated with policy transfer (Kern 2000; Tews 2002). Notwithstanding these conceptual overlaps, however, analytical differences between diffusion and transfer should not be overlooked. Diffusion and transfer studies differ considerably with regard to their level of analysis and their dependent variable. Diffusion studies usually adopt a macro-level perspective. Their dependent variables are general patterns of policy adoption within or across political systems. Analyses of policy transfer, on the other hand, focus on the underlying causes and contents of singular processes of bilateral policy exchange. The diffusion literature focuses more on the spatial, cultural and socio-economic reasons for particular adoption patterns rather than on the reasons for individual adoptions as such (Bennett 1991: 221; Jordana and Levi-Faur 2005). Diffusion studies often reveal a rather robust adoption pattern, with the cumulative adoption of a policy innovation over time following an S-shaped curve (Gray 1973).

From these considerations it follows that policy transfer and policy diffusion differ from policy convergence in important ways. First, differences exist with respect to the underlying analytical focus. While diffusion and transfer are concerned with process patterns, convergence studies place particular emphasis on outcomes. Transfer and diffusion thus reflect processes which under certain circumstances might result in policy convergence. This does not imply, however, that the empirical observation of converging policies must necessarily be the result of transfer or diffusion (Drezner 
2001). It is well conceivable that policy convergence is the result of similar but relatively isolated domestic events. Second, the concepts differ in their dependent variable. Convergence studies typically seek to explain changes in policy similarity over time. By contrast, transfer studies investigate the content and process of policy transfer as the dependent variable, while the focus of diffusion research is on the explanation of adoption patterns over time (Elkins and Simmons 2005; Gilardi 2005; Jordana and Levi-Faur 2005; Levi-Faur 2005).

The particular focus underlying the analysis of policy convergence places it in close proximity to the concept of isomorphism which has been developed in organisation sociology. Isomorphism is defined as a process of homogenisation that 'forces one unit in a population to resemble other units that face the same set of environmental conditions' (DiMaggio and Powell 1991: 66). The central question underlying studies on isomorphism refers to the mechanisms through which organisations become more similar over time. There is thus a broad overlap between studies on policy convergence and isomorphism, with the major difference between the two concepts being on their empirical focus and their level of analysis. The literature on isomorphism concentrates on organisational change and examines variations in similarity of organisational and institutional structures and cultures over time. Studies on policy convergence and diffusion, by contrast, focus on changes in national or state policy characteristics. Policy transfer studies also focus on policy characteristics.

The above considerations underline the need to apply a precise conception of policy convergence that allows for a clear differentiation between convergence and the related concepts of policy transfer, diffusion and isomorphism. We have seen that - notwithstanding certain overlaps - the concepts differ in considerable ways. Having clarified our understanding of policy convergence, the following section summarises existing empirical results with regard to policy convergence in the environmental field. 


\subsection{ENVIRONMENTAL POLICY CONVERGENCE - EMPIRICAL RESULTS}

Having discussed the relationship between policy convergence and other analytical concepts that are often used synonymously in the literature, we are still left with the question by which factors crossnational policy convergence is caused. What are the causal mechanisms behind environmental policy convergence? This question is addressed in the rest of this chapter. In a first step, this section will give an overview of the existing empirical findings on the transfer, diffusion and convergence of environmental policies As we will show, a rich body of diffusion and convergence studies has evolved in the field of environmental policy, turning this policy area into a major subject of convergence studies in general (see also Heichel, Pape and Sommerer 2005). In order to point out the disciplinary origins of the different studies, we broadly differentiate between the sub-fields of comparative politics on the one hand and international studies on the other.

Comparative studies originally focused predominantly on the national determinants of policy choice and policy change. Consequently, their theoretical point of departure was a general assumption of cross-national diversity of environmental policies due to different institutional frameworks, actor constellations, regulatory styles and problem pressures (Kitschelt 1983; Lundqvist 1974). However, comparative studies quickly detected that in spite of widely differing national styles of regulation, advanced industrial countries showed great similarities in deciding which risks required positive state action (agenda setting) and in their successes and failures to actually reduce environmental pollution (policy impacts) (Badaracco 1985; Brickman, Jasanoff and Ilgen 1985; Vogel 1986). While these studies did not directly pose the question of convergence or divergence of national environmental policies, their common finding of 'different styles, similar content' (Knoepfel et al. 1987) was a first step in that direction. In a summary of the findings of this first set of comparative environmental policy analyses Knoepfel et al. $(1987: 184)$ conclude 
that the hypothesis . . concerning the long-term convergence of policy outputs in environmental regulation must be tested and questioned in a more comprehensive analysis'.

Building on these early findings, a more recent set of comparative studies in the field of environmental politics began to systematically compare the development of domestic capacities for environmental policy-making throughout the entire group of Western industrialised countries. In an empirical assessment of the preconditions of effective environmental policy in OECD countries Jänicke found that besides domestic political, institutional and socioeconomic factors, global processes such as policy learning, diffusion and convergence had become independent sources of any country's capacity to address environmental problems (Jänicke 1992: 57, 1996: 281. Especially the creation of basic domestic institutions for environmental protection such as national environmental ministries, environmental protection agencies, general environmental laws or the adoption of environmental protection as a constitutional goal were highly influenced by the actions of international organisations such as the United Nations (UN) and by processes of imitation and learning among related countries. As a consequence, many Western industrialised states responded in a surprisingly homogeneous way to the environmental challenge that had entered the domestic and international policy agendas in the late 1960s and early 1970s (Jörgens 1996). A systematic in-depth comparison by Jänicke and Weidner across thirty industrialised and developing countries confirmed and extended these findings. It reveals a global convergence of governance patterns in environmental policy that covered not only domestic institutions, but also sectoral environmental laws, specific instruments, strategies, actor constellations and even the strengthening of societal capacities Jänicke and Weidner 1997; Weidner and Jänicke 2002). This convergence did not result from similar but independent reactions to comparable problem pressures, but rather from the increasing number, scope and activity of international environmental regimes and organisations. In addition, information about best practice 
in environmental protection is increasingly spreading not only among national policy-makers, but also among environmental nongovernmental organisations (NGOs), scientific experts and within the business sector (Weidner 2002: 1355-6).

While being increasingly aware of the growing importance of processes of cross-national policy convergence, comparative studies during most of the 1990 s still did not search systematically for processes of transfer, diffusion and convergence of environmental policies and their analysis was largely confined to ad hoc explanations. Conscious of these shortcomings, a new generation of studies began to focus explicitly on processes of cross-national diffusion and convergence of environmental policies. On the one hand, these studies were interested in the degree of convergence. On the other hand, they tried to identify the mechanisms that lead to cross-national convergence of environmental policies.

In a systematic analysis of the international diffusion of five selected environmental policy innovations [national environmental ministries, ecolabelling schemes, environmental strategies, $\mathrm{CO}_{2}$ taxes and soil protection laws) Kern, Jörgens and Jänicke (2000) find strong evidence for the importance of transnational imitation and learning as well as the impact of international institutions on the domestic adoption of environmental policies. However, the extent to which the five environmental policy innovations spread internationally varied considerably. Based on these empirical findings, the authors identify a complex set of explanatory factors including international dynamics as well as the specific domestic political and institutional contexts. In addition, they find that the properties of individual policy innovations and the structure of the underlying environmental problem strongly affect their transferability. The extremely slow spread of soil protection policies shows that low visibility of environmental problems and the lack of technological standard solutions can hamper the spread of regulatory initiatives. Similarly, redistributive policies like environmental taxes are likely to meet with strong 
domestic resistance and thus proliferate significantly more slowly than environmental ministries or information-based instruments.

These findings are confirmed and broadened by a subsequent comparison of the spread of twenty-two environmental policy innovations across forty-three countries from 1945 to 2000 (Busch and Jörgens 2005a, 2005b). Especially from the early 1970s a considerable extent of policy convergence can be observed throughout the OECD and Central and Eastern Europe $\mid \mathrm{CEE}$ | with strong peaks around the two major UN environmental conferences in 1972 and 1992 (see also Binder 2005: 207l. The main driving forces behind this convergence can be divided roughly into three analytically distinct groups of mechanisms operating at the inter- and transnational level: (1) voluntary imitation, rational lesson-drawing, 'scripted' behaviour based on a strong sense of appropriateness, and learning (i.e., diffusion in the narrow sense defined above); (2) compliance with binding European and international law (i.e., legal harmonisation); and (3) political or financial conditionality, for example during the process of EU enlargement (i.e., imposition) (for a distinction of these three groups of mechanisms see Bennett 1991; Busch and Jörgens 2005c; Busch, Jörgens and Tews 2005; Holzinger and Knill 2005b; Howlett 2000; Jörgens 2004; Tews 2005b). However, intemational driving forces did not affect all policy innovations and all countries alike, but were either enforced or hampered by the properties of individual policy innovations and a wide array of factors at the domestic level. Besides the three groups of international mechanisms, independent responses to pressing environmental problems also played an important role in the observed policy convergence.

In North America scholars have focused repeatedly on the transfer and convergence of environmental policies between Canada and the US. Hoberg and colleagues (Hoberg 1991; Hoberg, Banting and Simeon 1999) identify four types of international influence that promote convergence of Canadian environmental policy with the US: (1) international environmental agreements; (2) economic integration, 
including trade agreements such as the Canada-US Free Trade Agreement, NAFTA and the World Trade Organisation (WTO); (3) the cross-national transfer of ideas; and (4) cross-border lobbying by environmentalist groups. Focusing on implementation styles rather than policy outputs, Howlett (2000) finds a different pattern of environmental policy convergence between the US and Canada. Based on a comparison of three phases of US and Canadian environmental policy-making, he argues that a form of strong convergence is emerging, 'in which both countries are moving not towards each other but towards a third, common, style, that is associated with the development of self-regulation and voluntary initiatives under the influence of New Public Management ideas and principles' (Howlett 2000: 305). This 'emulation-based convergence' was spurred by general sets of policy ideas which circulated in the international sphere and had profound sectoral effects in both countries.

Besides the international system, the federal system of the US continues to be a major subject of convergence and especially diffusion studies. While some of the most influential work on policy diffusion was conducted in the American states (Berry and Berry 1990; Gray 1973; Mintrom 1997; Mintrom and Vergari 1998; Walker 1969], these studies rarely focused on issues of environmental policy. In a notable exception, Daley and Garand (2005) examine the spread of state programmes for the clean-up of abandoned hazardous waste sites. While the most urgent cases of soil contamination are addressed by the Federal Superfund programme, states are responsible for cleaning up the remaining hazardous waste sites in their jurisdiction. The article finds weak convergence where some states adopted strict programmes similar to the Federal Superfund while others opted for less ambitious programmes relying more strongly on voluntary initiatives. Testing both internal determinants and external diffusion hypotheses, the authors find state wealth, problem pressure and regional diffusion effects to be the most important determinants of strict state programmes. Moreover, they find that vertical diffusion from the federal to the state level has an important effect on state policy choices. 
While comparative studies started out looking for crossnational difference and found a surprising amount of similarity, Europeanisation research and international studies approached the subject of environmental policy convergence exactly the opposite way. Scholars of Europeanisation quickly detected that the powerful economic as well as political homogenising pressures within the EU do not necessarily lead to uniform action at the level of member states, but often produce a quite heterogeneous patchwork of institutions, instruments and policy styles (Héritier and Knill 2001). In a comparative assessment of environmental policies in ten EU member states, Jordan and Liefferink $(2004,2005)$ examine 'how far the EU has succeeded in encouraging the content, structure and style of national environmental policies to converge'. They find that, in spite of the enormous importance that the EU has acquired over the last decades in the field of environmental policy, only limited convergence of national environmental policies in the EU member states has occurred. The study shows that convergence is strongest with regard to the setting of individual environmental standards, a fact that is explained by the EU's ability to issue binding environmental legislation. The study also finds that 'some structural developments were shared by several member states, notably regarding the roles of national environmental ministries, national parliaments and NGOs' as a result of learning processes within the EU decision-making bodies. By contrast, however, 'national decision-making procedures, coordination mechanisms and political traditions ... have remained essentially the same in spite of EU membership' (Jordan and Liefferink 2005: 111).

In a similar study on the effects of European environmental and transport policies on national administrative styles and structures in the United Kingdom (UK) and Germany, Knill (2001) finds a varied pattern of change which includes elements of convergence towards a European model as well as divergence and domestic persistence. While a certain degree of Europeanisation of national administrations can be observed, deeply entrenched institutional traditions at the 
domestic level stand in the way of a more far-reaching convergence. Paradoxically, the impact of EU policies on national administrations grows and cross-national convergence increases as the degree of legal obligation of European policies declines. Ultimately, a European steering mode based on competition or communication proves superior to a 'coercive' approach as regards its impact on administrative convergence in EU member states (Knill and Lenschow 2005).

At the level of policy instruments Jordan et al. (2002) examine the spread of new environmental policy instruments (NEPIs - namely voluntary agreements and market-based instruments like eco taxes or tradable permits) in four EU member states and by the EU itself. In spite of a general increase in the use of voluntary and market-based instruments, the authors find little convergence with regard to the specific way these instruments are applied and implemented in the different national contexts and at the EU level. As in other Europeanisation studies, domestic institutional constraints are found to partially neutralise the international diffusion effects as 'states (and the EU) usually alter NEPIs transferred from elsewhere in order to ensure that they fit in with wider national (and supranational) institutional features and regulatory styles' (Jordan et al. 2002: 156).

In the field of international studies, the theoretically derived expectation of cross-national environmental policy convergence was most pronounced. However, the most widespread of these hypotheses, the prediction of a global race-to-the-bottom regarding environmental, consumer or worker protection, has repeatedly been challenged on empirical grounds. In his study on the relationship between trade policies and protective consumer and environmental regulation Vogel (1995, 1997) refutes the race-to-the-bottom hypothesis by showing that 'competition from nations with weaker environmental regulations has not prevented nicher, greener nations from strengthening their own regulatory standards' (Vogel 1997: 556). On the contrary, he finds substantial evidence that nations are increasingly adopting the stricter standards of their richer and greener trading partners. In a similar vein, but from an institutionalist perspective, Botcheva and 
Martin (2001) use the example of the Montreal Protocol on the Protection of the Ozone Layer to illustrate their theoretically derived hypothesis that the threat of significant negative environmental externalities, combined with strong international institutions which formulate clear environmental protection goals, provide transparency and secure compliance, will provide a strong incentive for countries to converge in their efforts to save the ozone layer. Both studies point towards a significant degree of environmental policy convergence at a high level of environmental protection.

In a large-scale empirical analysis Frank, Hironaka and Schofers $(2000)$ examine the global proliferation of five characteristic features of modern environmentalism - the creation of national parks, the establishment of national branches of international environmental associations, membership in intergovernmental environmental organisations, environmental impact assessment laws and the creation of national environmental ministries - over the twentieth century. Testing both for domestic and international factors they find that for all five measures the top-down international explanation provides a stronger explanation of the observable environmental policy convergence than the bottom-up domestic alternative. The authors interpret these findings as a sign of an ongoing redefinition of the constitutive idea of the modem 'nation state' to include environmental protection as one of its basic responsibilities. Especially countries with strong ties to world society prove to be receptive to this emerging global norm. In a similar vein, Meyer et al. (1997) describe the creation of a world environmental regime based predominantly on discourse, science and societal association. Contrary to the predominant approaches in international relations, nation states are not seen as constitutive elements of this world environmental regime. By contrast, the authors show that the regime evolved long before nation states entered the global environmental arena. Rather than shaping this global regime, nation states' attitudes towards environmental issues themselves are to a certain extent shaped by this global discourse. 'Most nation states had no central organised 
structures (such as ministries) dealing with the environment until late in the process. This reflects, in a sense, a top-down history, in which the rise of universalistic discourse and organisation rather belatedly construct nation states' aims and responsibilities more than the bottom-up political processes of power and interest that are mentioned more often' (Meyer et al. 1997: 645). While this study does not explicitly measure or explain environmental policy convergence, it describes a wider process of worldwide societal and governmental homogenisation with regard to the relationship of human society to nature.

\subsection{CAUSES OF CROSS-NATIONAL POLICY CONVERGENCE}

As has been shown in the previous section, the literature on environmental policy convergence and its related concepts offers a broad range of causal factors to explain changes in the similarity of policies across countries. At a very general level, these factors can be grouped into two categories: (1) causal mechanisms triggering the convergent policy changes across countries and (2) facilitating factors which affect the effectiveness of these mechanisms. The factors relevant in these two categories are summarised in table 2.2 and will be discussed in more detail in the following sections.

Table 2.2 Causal mechanisms and facilitating factors of cross-national policy convergence

Causal mechanisms

Independent problem-solving Imposition

International harmonisation

Regulatory competition

Transnational communication

Facilitating factors

Cultural similarity

Socio-economic similarity (income)

Pre-existing policy similarity 


\subsubsection{Causal mechanisms}

With respect to causal mechanisms, both the general literature on policy convergence and respective studies in the field of environmental policy emphasise rather similar aspects which refer basically to five central factors (cf. Bennett 1991; DiMaggio and Powell 1991; Dolowitz and Marsh 2000; Drezner 2001; Hoberg 2001; Holzinger and Knill 2004, 2005b).

First, cross-national policy convergence might simply be the result of similar, but independent responses of different countries to the same contextual factors. The major contextual factor in our field of research is parallel environmental problem pressure. Policy convergence then is caused by similar policy problems which countries react to independently (Bennett 1991: 231).

Second, emphasis is placed on the harmonisation of national policies through international or supranational law. Countries are obliged to comply with international rules on which they have deliberately agreed in multilateral negotiations.

Third, some studies emphasise convergence effects stemming from the imposition of policies. Imposition refers to constellations where countries or international organisations force other countries to adopt certain policies by exploiting asymmetries in political or economic power.

Fourth, regulatory competition emerging from the increasing economic integration of European and global markets has been identified as one important factor that drives the mutual adjustment of policies across countries.

Finally, cross-national policy convergence can be the result of transnational communication. Under this heading, several mechanisms are summarised which all have in common that they predominantly rest on communication and information exchange among countries (see Holzinger and Knill 2005b). They include lesson-drawing (where countries deliberately seek to learn from successful problem-solving activities in other countries), joint problem-solving activities within transnational elite networks or 


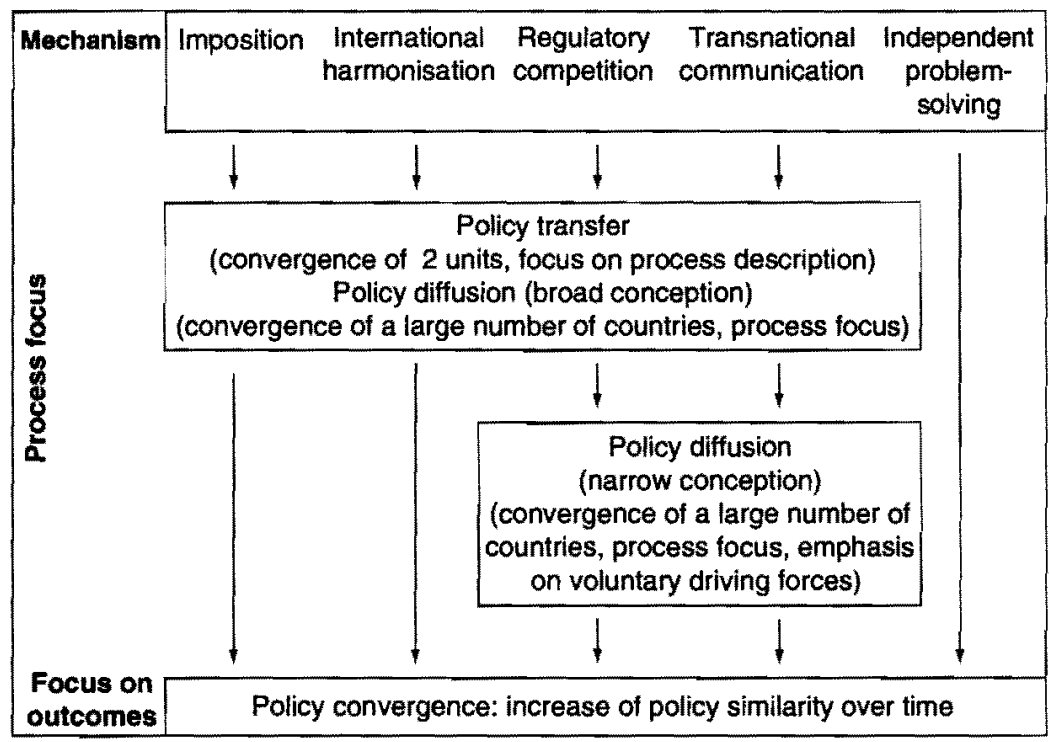

Figure 2.1 Causal mechanisms and the notions of policy transfer, diffusion and convergence

epistemic communities, the promotion of policy models by international organisations with the objective of accelerating and facilitating cross-national policy transfer, the emergence of widely accepted international norms of appropriate behaviour as well as the emulation of policy models.

In the latter case, one could certainly argue that communication is also of relevance with regard to the other mechanisms of imposition, international harmonisation or regulatory competition. In these cases, however, communication and information exchange are basically a background condition for the operation of the mechanisms rather than the central factor actually triggering convergence.

Figure 2.1 provides an overview of how the different causal mechanisms are linked to the concepts of convergence, diffusion and transfer discussed in section 2.2 above. As becomes apparent, not all causal mechanisms that might yield convergence are also relevant in bringing about transfer or diffusion. This holds true 
especially for independent problem-solving. Moreover, the figure illustrates the distinction between different concepts of policy diffusion. In contrast to the broad understanding of diffusion (which includes policy spreads triggered by imposition, harmonisation, regulatory competition as well as transnational communication!, the narrow conception restricts the phenomenon of diffusion to nonobligatory and non-coercive driving forces/regulatory competition and transnational communication).

\subsubsection{Facilitating factors}

What are potential facilitating factors that affect the degree of crossnational policy convergence? The first group of factors in that respect refers to characteristics, or more precisely, the similarity of the countries under investigation. It is argued that cultural similarity plays an important role in facilitating cross-national policy transfer. In their search for relevant policy models, decision-makers are expected to look to the experiences of those countries with which they share an especially close set of cultural ties (Lenschow, Liefferink and Veenman 2005, Strang and Meyer 1993). Moreover, similarity in socio-economic structures and the level of income has been identified as a factor that facilitates the transfer of policies across countries (see, for instance, on environmental policy, Jânicke 1998). Finally, the pre-existing policy similarity has been identified as a factor that influences the likelihood of convergence.

\subsection{CONCLUSION}

The overview of the state of the art with respect to the notion of policy convergence and related notions, empirical research on environmental policy convergence, and the causal mechanisms discussed in the convergence literature shows that there are still a number of research deficits.

First of all, empirical research on environmental policy convergence lacks studies comparing the development of the environmental 
policies in large numbers of countries and for extended periods of time. There are no quantitative studies of environmental policy convergence which are based on an encompassing data set of environmental policies. Thus, at the descriptive level we know that there has been diffusion of many policy innovations; however, we have only limited information as to what extent the environmental policies of many countries have in fact become more similar over time.

Second, there are no large-n studies of environmental policy convergence that analyse not only the degree of convergence, but also the direction of the convergence movement, that is, do countries move towards stricter environmental policies or do they lower their levels of protection? This is an important question, as theories of regulatory competition predict that under the conditions of a globalised economy there will be a race-to-the-bottom of environmental policies.

Third, in the environmental field there are so far no studies relying on a differentiated approach to the measurement of convergence. There are various conceptions of convergence, reaching from the simple idea that convergence is the decrease of variation over time to a notion of convergence that focuses on the catching-up of laggard countries. Moreover, there are no attempts to systematically measure the similarity of such complex things as environmental policy measures. While diffusion studies are only concerned with the adoption of a policy measure, like a policy against acid rain, the similarity of such a policy itself is not taken into account. For the study of convergence not only the presence of a policy but also its precise form is of interest. Which instruments are applied? At which level is a limit value set? Finally, in measuring convergence we should not restrict ourselves to metrical indicators, as this is easiest to deal with in statistical models.

Fourth, at the explanatory level, there is a lack of studies of environmental policy convergence that test and compare the effects of several causal factors of policy convergence in multivariate statistical models and that are based in the many theories of policy 
convergence put forward in the literature. Here it is important to test not only those factors where data are easily available (such as gross national product, trade openness, environmental expenditure or environmental quality datal, but to test those explanatory factors which seem to be most promising at the theoretical level, even if one has to collect the data and build new data sets beforehand.

Fifth, and with reference to the separation of the comparative and intemational studies of policy convergence, there is a lack of studies that take into account both international and domestic factors potentially explaining policy convergence.

Sixth, we need studies of environmental policy convergence that systematically analyse the variance in the similarity increase of different types of policies /such as different environmental media, trade-related versus non-trade-related policies) and of different dimensions of a policy /the instruments applied or the setting of limit values).

In view of these deficits this book aims at bringing together the two traditions of comparative and international studies of environmental policy transfer, diffusion and convergence. We focus on environmental policy convergence as this allows us to grasp all dimensions of environmental policy change. As figure 2.1 shows, convergence is the most encompassing perspective. Focusing on transfer, diffusion or isomorphism would lead us to neglect important aspects of environmental policy change.

In a large-n study we measure and explain the convergence of forty environmental policies in twenty-four mostly European countries over a period of thirty years. We do not restrict ourselves to measuring the extent and direction of policy convergence but we aim at explaining the increase in policy similarity by a whole bundle of potential driving factors of homogenisation of policies.

Our main research interest is in analysing three international causal mechanisms driving policy convergence: international harmonisation, transnational communication and regulatory competition isee figure 2.11. We do not take into account the mechanism of imposition 
because this does not play a significant role in environmental policy in Europe. Although some authors see the Eastern enlargement of the EU as a process of imposition or conditionality we prefer to classify the accession to the EU as part of the mechanism of international harmonisation (cf. chapter 3). Domestic factors that may influence processes of environmental policy convergence are controlled for. This way we grasp the mechanism of similar but independent responses to the same contextual factors, such as environmental problem pressure or political demand for environmental protection.

The three causal mechanisms we intend to analyse correspond to three theories predicting policy convergence: theories of international cooperation, theories of cross-national policy learning and the theory of regulatory competition. All of these theories have a micro-foundation: national governments are the main actors bringing about policy change. With this background the data to be explained in our study are policy output data rather than policy outcome data. We are interested in changes in the actual policies adopted by government, not in changes of the environmental quality. Changes in environmental quality may be brought about by many factors not related to theories of cross-national policy convergence, such as implementation deficits or increase in behaviour damaging the environment.

Finally, we apply a careful and multifold approach to the measurement of convergence. First, we collect data on several dimensions of a policy (the adoption, the instrument used and the exact setting of values) in order to grasp the similarity of policies and policy repertoires as deeply as possible. Second, we develop two innovative conceptions of convergence measurement:

(1) The pair approach: In this concept we measure the degree of convergence on the basis of a comparison of all country pairs for each policy, an approach that avoids a number of methodological problems of classical measurement of sigma-convergence. 
(2) The gap approach: In this concept we measure the direction of convergence by analysing the changes in distance of countries to the environmental front-runner country for a given policy.

Both approaches together allow us to provide a differentiated picture of the degree and direction of environmental policy convergence in Europe and its causes. This way we are able to provide a new contribution to the explanation of environmental policy convergence in Europe. 